\title{
Facility management and building information modeling during operation and maintenance
}

\author{
Michal FALTEJSEK ${ }^{*}$, and Blanka CHUDIKOVA \\ VŠB - Technical University of Ostrava, Faculty of Civil Engineering, Ludvíka Podéště 1875/17, \\ Ostrava-Poruba, 708 33, Czech Republic
}

\begin{abstract}
BIM is a concept and also a method currently applied throughout the world in the modern building construction. The impact and benefits of the BIM method are clear across all stages of the life cycle of buildings (project, realization, operation, demolition). The longest and most expensive phase of buildings life is the operation and usage part. Many common aspects and linkage of processes between the BIM method and the facility management, i.e. a modern asset management method, can provide greater efficiency for these activities, help reduce the cost of required building operations and maintenance and save time for individual activities. The BIM can be understood as an information management of buildings. Many common elements can create a synergy of processes related to the management of buildings. The article discusses these aspects and emphasizes the listing of the basic data and processes that are necessary for mutual interconnectedness.
\end{abstract}

\section{Introduction}

Operation and maintenance of buildings are the longest and most expensive parts of the life cycle of buildings. They are parts of many processes that must work efficiently, clearly and sustainably in the long run. The life of buildings is in the order of decades, and throughout the period it is necessary to maintain a standard for the users of these buildings. Properly set up facility management processes using efficient and effective methods can help extend the useful life of buildings and delay their degradation. One of these methods that can be applied is BIM method, i.e. Building Information Modeling / building management.

BIM is a concept that brings a new look at the life cycle of buildings. BIM method can be applied in two ways. The first is the implementation of BIM method already in the construction project, through implementation and then in operation and maintenance. This can only be applied to new constructions. For buildings that are already built, we need to implement BIM afterwards. BIM implementation process for existing buildings may vary, depending on the available documentation, information, software used, data formats, the level of detail, or the expected benefit. f[1]

The procedures and methods for implementing BIM in these two cases are different. For already constructed buildings, the data is available at the very beginning of BIM implementation process, as well as the construction, equipment and overall construction.

\footnotetext{
*Corresponding author: michal.faltejsek@vsb.cz
} 
Most of the companies that has launched BIM is still focused on implementing this concept in designing and constructing new buildings. [2]

To optimize the facility management processes it is necessary to provide a detailed overview of structures and elements, and the general state of the buildings already built. This guarantees BIM and, if properly managed, guarantees long-term benefits in many forms. Individual activities of a facility management can be simplified by BIM to achieve greater work efficiency, reduce time for individual activities and cut down costs. [3]

BIM is also about cooperation. Co-operation and correctly set procedures and processes already at the implementation stage of BIM can be crucial for the following work and maintenance of BIM. Just as designers and developers of buildings should communicate with the end user and facility manager, i.e. to take into account the following stages of the building life cycle, the future work with BIM model (including maintenance and updates) should also be made provision for in the creation of an additional BIM model and its implementation into the facility management. The implementation of BIM should then be built on that. [4]

\section{Detailed passportization of property}

The real asset overview and its technical and economic features are key to the proper functioning of facility management. This requires high-quality passportization of the existing building. A passportization itself is a process consisting of several sub-parts. First of all, it is necessary to gather the available documents, sort them out and check their up-todateness. The next step is to fill in the missing information. Mostly by a personal survey of the building or by obtaining it from external sources.

It is also useful to take a photo of individual facilities, especially the technical equipment, and enclose it to an element in the CAFM system as an attachment. This ensures checking and a better overview of the equipment, its location in the space, attachment(s), components, etc.

Personal research is time-consuming and requires access to individual spaces. In rooms, it may be difficult to locate or physically access the searched for elements. They may be under lock and key or covered. In many cases they might not be in places indicated by available data. All this information has to be recorded and then re-edited into the correct structure and assigned to the corresponding areas (if it involves checking a facility).

\subsection{Quality records and data sources}

Quality records of managed assets' data are a basic prerequisite for the efficiency and costeffectiveness of downstream activities. Quality level of records is a very important element in any property management. The records should be uniform, comprehensive, clear, of high-quality and standardized. In the service life cycle of buildings, we assume a long-term records of assets. That's why their accuracy and up-to-dateness is necessary. [5]

The quality level of the records serves as a prevention of error-making by decisions that ultimately may have negative impacts due to lack of information and associated poor evaluation. This creates additional cost items associated with removing or correcting errors.

Data sources should be in the first place verified and up-to-date. For example, the sources can include:

1. Electronic drawing documentation

2. Digitization of paper drawing documentation

3. Physical data collection on site

4. Suppliers of design services

5. Construction contractors 
6. Suppliers of technical equipment and technologies

7. Service suppliers

8. General Central Registers (Land Registry, Territorial Identification Registry of Addresses, Registers of Economic Bodies, Roads Register) [6]

\section{Information model of building in facility management}

The interconnectedness of facility management and BIM methods is primarily in data. The BIM model forms a basic graphical and informative basis for managed asset. Facility management and support software (CAFM systems) provide detailed inventory of assets and enable planning of processes and operation and maintenance activities. The interrelation of these activities is therefore indisputable and lies above all in data that allow better visualization in a BIM model environment, refurbishment or modernization planning, their status verification, provide accessibility, etc. [3]

Digital background information created in 2D CAD software can be a good basis for BIM creation. This is evidenced by the claim that the introduction of BIM for existing buildings (with 2D only documentation) is possible with the use of this background information and there is no need to create a completely new model and without background material.

The 3D model itself does not yet form BIM, but only a suitable background. At present, "Information Building Management" is increasingly mentioned instead of "Information Modeling of Buildings", which shifts the importance to the information and subsequent work with it rather than to the 3D model itself. However this does not mean we should do $\mathrm{BIM}$ without a $3 \mathrm{D}$ model. Its use is wide and the creation of such a model in accordance with the BIM concept is therefore desirable for facility management.

\subsection{Additional BIM building model creation}

Original drawings of a building usually in 2D serve as a basis for creating a 3D model (figure 1). This drawing will be a ground plan of the future model and will guarantee the retention of the ground plan dimensions, equipment layout, etc.

In the Revit software it is very easy to create such a background from a DWG drawing. For individual floors a corresponding drawing is always attached of the modelled floor and aligned with the preceding floor so that the individual floors link to each other when drawn in $3 \mathrm{D}$ (that is why it was necessary to modify individual $2 \mathrm{D}$ drawings).

The model is drawn on the basis of a defined LoD and the available software options. For example, structures and rough construction can be drawn in a very detailed and realistic way. For specific types of devices and other equipment, there may be a problem with the model. Atypical shapes and many kinds of equipment (such as chairs, tables, cabinets, but also technical equipment) are often not available in libraries. Also, in cases of existing buildings the equipment is mostly obsolete and not produced anymore, therefore not available. In such cases, the placeholder model of a universal element can be applied and distinguished only by the information / description. Another option may be to create your own model. However, it is very labor-intensive and the efficiency / time ratio shows that it is usually not worth it. [1] 


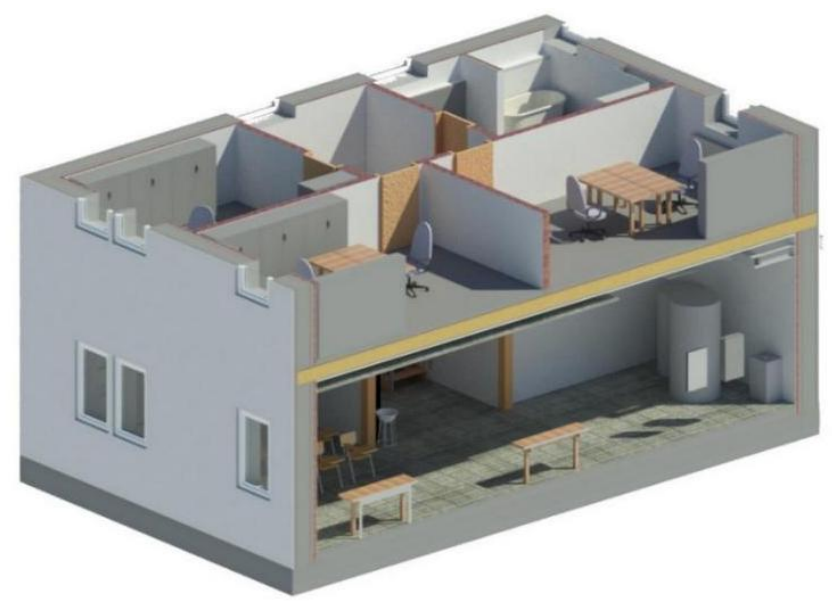

Fig. 1. 3D graphic model of the MSDK building (author, Autodesk Revit software).

\subsection{Adding basic information to individual elements}

What constitutes BIM is the information. It is important, therefore, that individual elements of the model should be enriched by the information or be properly interconnected with such information (figure 2). Some information may be inserted directly into the model, but if there is much of information to the individual elements it is more appropriate to feed it into the CAFM system and link it to the graphical model. [2]

Therefore, only basic but important information is included in the model. It may be information about material, colour, type of equipment, or price. Naturally there is also information on the dimensions and location of the equipment.

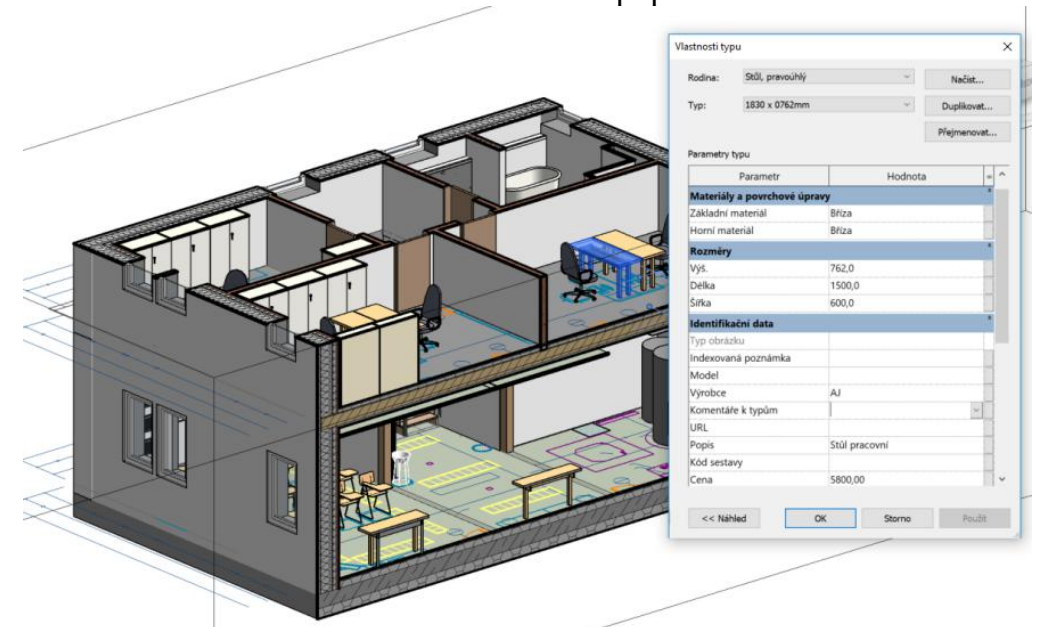

Fig.2. Information in the 3D model of construction for individual elements (Author, Autodesk Revit software).

\section{CAFM systems and BIM}

Computer Aided Facility Management are systems that should make facility management's asset management work easier. These systems are mainly used to manage the FM support processes, their clarity of records and any planning and evaluation. CAFM systems are 
continually improving to meet more modern and newly incoming customer requirements. It could be said that due to the development of systems around the world, we should only designate true CAFM system only those systems that feature a statistical, dynamic and output data area. These are, above all, systems that cover all known areas of support processes.

The CAFM systems' deployment aims in particular to:

- reduce operating costs,

- improve the quality of services provided and improve the quality of the environment,

- $\quad$ optimize the relationship between worker, environment and processes,

- extend the life of the monitored constructions and objects,

- introduce standards, rules and working processes in the given field and in the system of embedded business logic,

- introduce and distribute internal costs and their assignment to departments, divisions, activities, projects, etc.,

- manage and maintain documentation, moves, benchmarking, inventory and inspection,

- $\quad$ prepare for unexpected events and accidents, processes required by legislation (audits, inspections, ...), sustainable development. [6]

\subsection{Connecting to a CAFM system}

The 3D BIM model itself is not sufficient enough and needs to be linked to the CAFM system. This allows for the mutual localization of the elements: from the model to the CAFM system and vice versa, the exchange of information again in both directions, or the possibility of colouring the search areas. CAFM (Computer Aided Facility Management) is a facility management system with a wealth of different asset management functions (reactive and proactive maintenance, planning of activities, inventory of small and investment assets, migration planning, room reservation, key management, OSH and FS, waste management etc.).

\section{Linking BIM and Facility Management Processes}

The first step is to implement existing FM processes to the BIM model and the CAFM system. Thus, we create typical operations and maintenance activities in relation to the areas and equipment we know and that are already being routinely used.

The main interaction consists in visualizing the data into the graphical realistic form of the building. With the help of virtual reality, this effect can be further enhanced. Facility management can save the facility managers a lot of time in the case of large complexes and complicated buildings when they need not go through the building personally to see the individual facilities, the layout of the equipment in the rooms, the accessibility of the individual facilities, etc., as a clear and realistic visualization in BIM model with a link to all important data in the CAFM system is for such tasks sufficient. Also, all changes (reconstruction, upgrading, transfers, moving, etc.) can be planned through the BIM model thus creating options for subsequent final decisions.

Basic facility management activities that can be applied:

- reactive maintenance - ad hoc troubleshooting and repairs

- proactive maintenance - planned inspections and checks

- management of lease relations

- energy, media and consumption meter management 
- key management

- waste management

- OSH and FS

- cleaning of spaces and elements

- management of held events

- room reservations, room occupancy (offices by internal / external staff)

- document management system (document administration) [6]

There are many activities falling under facility management. Generally speaking, their task is to ensure that the subject and its staff are carefree, so they do not have to worry about dealing with the above-mentioned activities in any way.

In the CAFM system, you need to define the processes to support the respective FM activity (listed above, but also others that are not mentioned here but are associated with asset management, operation, and maintenance). The linking of activities and their records in the CAFM system will ensure greater clarity, traceability and access to follow-up information (by whom and when the activity is performed, for what purpose, which documents are attached to the activity, responsible persons or entities contact particulars, further information on the managed element, etc.).

\subsection{Optimization of Facility Management Processes}

The optimization involves primarily analysis and evaluation of results / comparison with the original state. For this purpose it is advisable to pre-determine the quantities that we will track over time and compare. On this basis, it is possible to define the differences and clearly define the gaps in the individual processes. You can then optimize these based on your experience, options and data.

Optimization is a long-term and repetitive process. It is necessary to have the process set for some time and to monitor and record it in detail. After performing optimization (change), it is necessary to again analyze and track newly established procedures, which are then compared with the original ones and their contribution evaluated.

In the long run the overview makes it much easier to evaluate and analyze facility management processes, track back their workflows, and then optimize them accordingly. [6]

\section{Conclusion}

On the whole, facility management and use of the BIM model offers clarity: if we have a large complex and are looking for a specific facility, room or equipment, we can easily visualize this element or person through the CAFM system and display it in a 3D model. Realistic graphical depiction will help to avoid lengthy search and visualization during team work will help without having to physically visit a particular part or equipment.

Other uses may be in the colouring of areas: e.g. planning for cleaning or moving, reconstruction and upgrading (e.g. colouring of all areas where the floor covering is tiled or where a non-load-bearing partition of $100 \mathrm{~mm}$ thickness is used, etc.).

Using a BIM model interconnected with CAFM system during modernization and reconstructions we can plan the work activities, the applicable bill of quantities and find out where the technical building installation systems are concealed in walls, what the properties of the current structure are, what materials have been used, and much more.

An important element for the operation and collaboration of facility management and BIM method is the aspect of the data update. BIM itself, if it remains inactive, lacks sense in the long term. This problem is very common in new constructions, when a BIM model was created and the data passed to the implementation stage. Based on the BIM concept, 
the construction is subsequently implemented, but most of the time the BIM process ends there and does not continue into the operation and maintenance phase. Which is a problem that is still very much underestimated. Yet, the operating phase of the construction is the longest and most costly part of the life cycle during which the wide scope of the BIM model and data use could be utmost beneficial.

\section{Acknowledgement}

This work was supported from the funds of the Students Grant Competition of the VSB Technical University of Ostrava. Project registration number is SP SP2018/113.

\section{References}

1. BRUMANA R, DELLA TORRE S, PREVITALI M, BARAZZETTI L, CANTINI L, ORENI D and BANFI F. Generative HBIM modelling to embody complexity (LOD, LOG, LOA, LOI): surveying, preservation, site intervention-the Basilica di Collemaggio (L'Aquila). Applied Geomatics. 2018, 10(4), 545-567, DOI: 10.1007/s12518-018-0233-3. ISSN 1866-9298. Available from: http://link.springer.com/10.1007/s12518-018-0233-3

2. SMITH, DANA $K$ and TARDIF $M$. Building information modeling: a strategic implementation guide for architects, engineers, constructors, and real estate asset managers. Hoboken, NJ: Wiley, 2009, ISBN 978-0-470-25003-7.

3. Černý M a kol. BIM př́ručka, 1. vydání, Praha, 2013, ISBN 978-80-260-5297-5, s. 80.

4. SANCHEZ A X, HAMPSON K D and VAUX S. Delivering Value with BIM, A whole-oflife approach. London a New York: Routledge, 2016. ISBN: 978-1-13811899-7.

5. EASTMAN Ch, TEICHOLZ P, SACKS R and LISTON K. BIM Handbook, A Guide to Building Information Modeling for Owners, Managers, Designers, Engineers, and Contractors. New Jersey: John Wiley \& Sons, Inc, 2008. ISBN: 978-0-470-18528-5.

6. Kuda F, Beránková E and Soukup P.. Facility management v kostce pro profesionály i laiky, nakladatelstvi FORM Solution, 2012, první vydání, ISBN 978-80905257-0-2. 